\title{
Integrating sexual and reproductive health and rights package in national health policies, programmes and practices in the Eastern Mediterranean Region ${ }^{1}$
}

Citation: Integrating sexual and reproductive health and rights package in national health policies, programmes and practices in the Eastern Mediterranean Region. East Mediterr Health J. 2019;25(10):763-764 https://doi.org/10.26719/2019.25.10.763

Copyright @ World Health Organization (WHO) 2019. Some rights reserved. This work is available under the CC BY-NC-SA 3.0 IGO license (https:// creativecommons.org/licenses/by-nc-sa/3.o/igo).

\section{Introduction}

A consultative meeting and workshop on adopting an integrated sexual and reproductive health and rights (SRHR) package in national health policies, programmes and practices in the Eastern Mediterranean Region were held in Tunis, Tunisia, from 8 to 13 July 2019 (1). The meeting and workshop were organized by the World Health Organization (WHO) Regional Office for the Eastern Mediterranean, Cairo, Egypt.

The objectives of the meeting and workshop were to:

- examine the situation of SRHR national policies, programmes and practices in participating countries;

- define the scope of an integrated SRHR package to be adopted by Member States;

- discuss programmatic approaches for integrating an SRHR package in existing national services;

- build the capacity of national staff in mechanisms and approaches for integrating the SRHR package into health policies and practices; and

- develop country plans for the adaptation and implementation of the integrated SRHR package.

The event was attended by 54 participants from six countries (Afghanistan, Egypt, Islamic Republic of Iran, Morocco, Pakistan, Tunisia), in addition to representatives from United Nations Children's Fund (UNICEF), United Nations Population Fund (UNFPA), International Planned Parenthood Foundation (IPPF) and WHO.

The meeting was inaugurated by Dr Chokri Hamouda, Director, Primary Health Care, Ministry of Health, Tunisia, who emphasized the need for multisectoral collaboration between all concerned stakeholders in the public, private and civil society sectors.

Dr Rafla Tej Dellagi, President and Director General of the National Board of Family and Population, Tunisia, highlighted the need for improving accessibility to SRHR services and the importance of structured action to reduce maternal and neonatal mortality due to preventable causes. Dr Dellagi emphasized that the sharing of experiences and learning from success stories would expedite the journey towards achieving the Sustainable Development Goals (SDGs).

The message of Dr Ahmed Al-Mandhari, WHO Regional Director for the Eastern Mediterranean, was delivered by Dr Yves Souteyrand, WHO Representative in Tunisia. In his message, Dr Al-Mandhari noted that improving SRHR was a key strategy to eliminating preventable maternal mortality and morbidity through the implementation of up-to-date, evidence-based and high-impact interventions that ensure the provision of quality sexual and reproductive health care, including family planning services and post-abortion care. He noted that universal access to sexual and reproductive health was essential not only to achieving the SDGs, but also for ensuring people's full enjoyment of health and human rights.

\section{Summary of discussions}

The essential components of a comprehensive SRHR package were identified. These include comprehensive reproductive health and sexuality education; preconception care; counselling and services for a range of modern contraceptives; antenatal, child birth and postnatal care, including emergency obstetric and newborn care; safe abortion services and post-abortion care; prevention and management of HIV and other sexually transmitted infections (STIs); prevention, detection, immediate services, referrals and management for cases of sexual and gender-based violence; prevention, detection and management of reproductive system cancers, especially cervical cancer; information, counselling and services for subfertility and infertility; and information, counselling and services for sexual health and well-being.

WHO identified a number of evidence-based interventions for various components of an SRHR package. Participants reviewed these to agree on core and extended interventions to be implemented in the Region.

Laws, regulations and policies related to SRHR in the Region were identified. Most countries have a legal and policy imperative to provide SRHR services, although these are often not comprehensive or implemented and monitored in the way prescribed.

\footnotetext{
This summary is extracted from the report on the Consultative meeting and workshop on adopting an integrated sexual and reproductive health and rights package in national health policies, programmes and practices in the Eastern Mediterranean Region, Tunis, Tunisia, 8-13 July 2019 (http://applications.emro.who.int/docs/IC_Meet_Rep_2019_WRH_108_en.pdf?ua=1).
} 
The importance of reviewing laws and policies related to SRHR in countries was highlighted, as was the need to establish monitoring frameworks to identify gaps and challenges that may hinder the implementation of a comprehensive SRHR package.

Global frameworks that include SRHR indicators were discussed, including the SDG monitoring framework (2) and monitoring of the Global Strategy for Women's, Children's and Adolescents' Health (2016-2030) (3).

It was agreed that Integration of SRHR interventions into existing programmes and service delivery packages will improve the accessibility and availability of SRHR services, and reduce costs and maximize the use of already limited human resources.

\section{Recommendations}

\section{To WHO}

- Finalizing the technical guidance document for integrating SRHR packages into policies, programmes and practices in the Region.

- Translating the compilation of WHO recommendations on sexual and reproductive health into Arabic and French.

- Providing the required technical support and guidance during the national process of integrating SRHR interventions into policies, programmes and practices.
- Designing a digital interactive platform for integrating SRHR interventions into policies, programmes and practices.

\section{To Member States}

- Identifying gaps and priorities in national SRHR policies, programmes and practices, and the action needed to address them in the context of national commitments on universal health coverage, and undertaking advocacy to ensure national support.

- Ensuring a strong coordination mechanism with key stakeholders to achieve optimal impact and avoid duplication of efforts.

- Identifying gaps in national laws, regulations and policies, and trying to address them to ensure provision of integrated SRHR services for all.

- Building on existing opportunities to reach all through universal health coverage for SRHR, such as digital health and SRHR self-care.

- Ensuring the inclusion of SRHR indicators, with clear definitions and means of verification, in national monitoring frameworks.

- Creating awareness among the general public of SRHR using low-cost techniques such as social media campaigns.

\section{References}

1. Consultative meeting and workshop on adopting an integrated sexual and reproductive health and rights package in national health policies, programmes and practices in the Eastern Mediterranean Region, Tunis, Tunisia, 8-13 July 2019 (http://applications.emro.who.int/docs/IC_Meet_Rep_2019_WRH_108_en.pdf?ua=1).

2. World Health Organization Regional Office for the Western Pacific. Regional monitoring framework. Manila: WIPRO; 2017.

3. United Nations. Every woman every child: the global strategy for women's, children' and adolescents' health (2016-2030). New York: United Nations; 2015 (https://www.who.int/life-course/partners/global-strategy/globalstrategyreport2016-2030-lowres. pdf?ua=1). 